\title{
Patient misconceptions concerning lumbar spondylosis diagnosis and treatment
}

\author{
Eric W. Franz, BS, ${ }^{1}$ J. Nicole Bentley, MD, ${ }^{2}$ Patricia P. S. Yee, BS, ${ }^{2}$ Kate W. C. Chang, MA, ${ }^{2}$ \\ Jennifer Kendall-Thomas, DO, ${ }^{2}$ Paul Park, MD, ${ }^{2}$ and Lynda J. S. Yang, MD, PhD ${ }^{2}$
}

1Wayne State University School of Medicine, Detroit; ${ }^{2}$ Department of Neurosurgery, University of Michigan, Ann Arbor, Michigan

\begin{abstract}
OBJECT Patient outcome measures are becoming increasingly important in the evaluation of health care quality and physician performance. Of the many novel measures currently being explored, patient satisfaction and other subjective measures of patient experience are among the most heavily weighted. However, these subjective measures are strongly influenced by a number of factors, including patient demographics, level of understanding of the disorder and its treatment, and patient expectations. In the present study, patients referred to a neurosurgery clinic for degenerative spinal disorders were surveyed to determine their understanding of lumbar spondylosis diagnosis and treatment.
\end{abstract}

METHODS A multiple-choice, 6-question survey was distributed to all patients referred to a general neurosurgical spine clinic at a tertiary care center over a period of 11 months as a quality improvement initiative to assist the provider with individualized patient counseling. The survey consisted of questions designed to assess patient understanding of the role of radiological imaging in the diagnosis and treatment of low-back and leg pain, and patient perception of the indications for surgical compared with conservative management. Demographic data were also collected.

RESULTS A total of 121 surveys were included in the analysis. More than $50 \%$ of the patients indicated that they would undergo spine surgery based on abnormalities found on MRI, even without symptoms; more than $40 \%$ of patients indicated the same for plain radiographs. Similarly, a large proportion of patients (33\%) believed that back surgery was more effective than physical therapy in the treatment of back pain without leg pain. Nearly one-fifth of the survey group $(17 \%)$ also believed that back injections were riskier than back surgery. There were no significant differences in survey responses among patients with a previous history of spine surgery compared with those without previous spine surgery.

CONCLUSIONS These results show that a surprisingly high percentage of patients have misconceptions regarding the diagnosis and treatment of lumbar spondylosis, and that these misconceptions persist in patients with a history of spine surgery. Specifically, patients overemphasize the value of radiological studies and have mixed perceptions of the relative risk and effectiveness of surgical intervention compared with more conservative management. These misconceptions have the potential to alter patient expectations and decrease satisfaction, which could negatively impact patient outcomes and subjective valuations of physician performance. While these results are preliminary, they highlight a need for improved communication and patient education during surgical consultation for lumbar spondylosis.

http://thejns.org/doi/abs/10.3171/2014.10.SPINE14537

KEY WORDS back pain; lumbar spondylosis; misconceptions; patient expectations; patient satisfaction

$\mathrm{T}$ He Institute of Medicine's 1999 report, To Err is Human: Building a Safer Health System, documented the prevalence and consequences of medical errors within the health care system and helped to launch the current health care reform movement. In the following years, health care providers and organizations developed and implemented a multitude of quality improvement strategies. ${ }^{11}$ One of these strategies, known as Pay-for-Performance, has become increasingly prominent in the national health care dialogue. Pay-for-Performance measures comprise several metrics examining the outcome of the patient-provider-institution interaction. Among these, "patient expe- rience" incorporates a subjective rating of the patient's satisfaction with their experience that may or may not correlate with physician-measured clinical outcomes. Although difficult to quantify, previous research has demonstrated that patients' satisfaction with their experience can impact clinical outcomes, predict malpractice litigation, and influence doctor switching. ${ }^{1,2,22}$ Additionally, in recent years, satisfaction measures have been used to directly monitor health care outcomes and quality. ${ }^{8}$

Patient satisfaction can itself be influenced by a number of different factors, including patient expectations, demographic and personal characteristics, patients' knowledge 
of their condition, and interpersonal and technical aspects of care. ${ }^{2,17,19}$ Of these, patient expectations are among the most important factors contributing to patient-reported satisfaction with medical care. ${ }^{1,15,23}$ For example, studies demonstrate that when patients present to their physician intending to request specific tests or expecting to undergo certain tests, and these services are not provided, patient satisfaction decreases. ${ }^{1}$ Additionally, patients with low satisfaction and unmet expectations report less of an intention to adhere to physician advice, and have a greater tendency to use the health care system. ${ }^{22,23}$

In the present study, we demonstrate the existence of misconceptions potentially leading to unmet expectations in the treatment of lumbar spondylosis. Identifying and addressing these misconceptions are critical components for improving communication and education between physicians and patients and can aid in circumventing many barriers to providing informed, quality health care. Furthermore, given the rising prevalence of patient-reported subjective outcome measures, it is becoming increasingly important to acknowledge and address these misconceptions to better manage expectations and to educate both patients and referring physicians about degenerative spinal disorders.

\section{Methods \\ Study Participants}

This study was approved by and performed in accordance with the University of Michigan Institutional Review Board under a quality improvement exemption. Surveys were distributed to all new patients referred to a single neurosurgeon (L.J.S.Y.) for evaluation of spinal spondylosis between June 2012 and April 2013. All patients presented with a chief complaint of "back pain" with or without leg pain. Patients were excluded if they had any prior interaction with the surgeon.

\section{Data Collection}

The survey contained 6 multiple-choice questions designed to assess patient understanding regarding lumbar spondylosis (Table 1). For the first 2 questions concerning radiological imaging, survey participants who chose more than 1 answer were excluded from the analysis. For the remaining questions concerning the risk and effectiveness of various treatment options, survey participants who chose both answers were considered to believe both treatment options were equally risky/effective. Demographic data were also obtained, and proximity to the fungal meningitis outbreak linked to contaminated spinal injections was recorded, as this was believed to be a possible confounding variable.

\section{Statistical Analysis}

Descriptive statistics included patient demographics and questionnaire responses. Patients were divided into groups according to demographic variables: age, sex, education (high school, college, graduate/professional school), history of back surgery, and date of survey completion (relative to the selected meningitis outbreak date). For group comparison of continuous variables such as age, the Student
TABLE 1. Survey instrument designed to assess patient understanding regarding lumbar spondylosis

1. Would you be willing to undergo surgery if your MRI reports abnormalities, even if you do not have any symptoms?

A) Yes or B) No

2. Would you be willing to undergo surgery if your $\mathrm{x}$-ray reports abnormalities, even if you do not have any symptoms?

A) Yes or B) No

3. Which is more effective to treat back pain (not leg pain)?

A) Back surgeries or B) Physical therapy

4. Which has more risk?

A) Back injections or B) Back surgeries

5. What is your highest level of education?

A) High school or B) College or C) Graduate/professional school

6. Have you undergone spine (back or neck) surgery?

A) Yes or B) No

t-test was used. Chi-square tests were used for the remaining categorical variables. All statistics were performed using SPSS software (version 21, IBM Inc.), and p values less than 0.05 were considered statistically significant.

\section{Results}

A total of 121 surveys were analyzed. Table 2 displays patient demographics. Mean patient age and standard deviation was $54 \pm 16$ years. Sex and patient education level were relatively evenly distributed, and participants with a history of prior back surgery represented one-third (32\%) of survey respondents.

Demographic distributions of the survey responses for the first 2 questions are presented in Tables 3 and 4 . In response to the first question, "Would you be willing to undergo surgery if your MRI reports abnormalities, even if you do not have any symptoms?," 114 surveys revealed

TABLE 2. Demographics of patients responding to the survey

\begin{tabular}{lc}
\hline \multicolumn{1}{c}{ Parameter } & No. of Patients (\%) \\
\hline Total no. of patients & 121 \\
\hline Average age \pm SD (yrs) & $54 \pm 16$ \\
\hline Sex & $64(53)$ \\
\hline Male & $57(47)$ \\
\hline Female & \\
\hline Education* & $46(38)$ \\
\hline High school & $45(37)$ \\
\hline College & $30(25)$ \\
\hline Graduate or professional & $39(32)$ \\
\hline Received back surgery & $82(68)$ \\
\hline Yes & $70(58)$ \\
\hline No & $51(42)$ \\
\hline Date survey completed
\end{tabular}

* One survey participant did not report education level. 
TABLE 3. Demographics of respondents to the following question: Would you be willing to undergo surgery if your MRI reports abnormalities, even if you do not have any symptoms?

\begin{tabular}{|c|c|c|c|c|}
\hline Parameter & All Responses & Yes & No & $\mathrm{p}$ Value \\
\hline Total respondents (\%) & $114^{*}$ & $59(52)$ & $55(48)$ & - \\
\hline Average age \pm SD (yrs) & $54 \pm 16$ & $53 \pm 17$ & $54 \pm 15$ & $0.66 \dagger$ \\
\hline $\operatorname{Sex}(\%)$ & & & & $0.1 \ddagger$ \\
\hline Males & $63(55)$ & $37(63)$ & $26(47)$ & \\
\hline Females & $51(45)$ & $22(37)$ & $29(53)$ & \\
\hline Education $(\%) \S$ & & & & $0.74 \ddagger$ \\
\hline High school & $42(37)$ & $20(34)$ & $22(40)$ & \\
\hline College & $43(38)$ & $24(41)$ & $19(35)$ & \\
\hline Graduate or professional & $28(25)$ & $15(25)$ & $13(24)$ & \\
\hline Received back surgery (\%) & & & & $0.88 \ddagger$ \\
\hline Yes & $36(32)$ & $19(32)$ & $17(31)$ & \\
\hline No & $78(68)$ & $40(68)$ & $38(69)$ & \\
\hline Date survey completed (\%) & & & & $0.37 \ddagger$ \\
\hline Before fungal meningitis outbreak & $65(57)$ & $36(61)$ & $29(53)$ & \\
\hline After fungal meningitis outbreak & $49(43)$ & $23(39)$ & $26(47)$ & \\
\hline
\end{tabular}

* Seven survey participants did not respond and were excluded from analysis.

$\dagger$ Student t-test used for group comparison.

$\ddagger$ Chi-square test of independence applied for group comparison.

$\S$ One survey participant did not report educational level and was excluded from chi-square analysis.

that in the absence of any symptoms, 59 patients (52\%) would be willing to undergo surgery based on reported MRI abnormalities. There were 116 responses to the second question, "Would you be willing to undergo surgery if your x-ray reports abnormalities, even if you do not have any symptoms?" Response results were similar to those recorded for the previous question concerning MRI find- ings, with $41 \%$ of patients indicating they would elect to have surgery based on abnormalities found on plain radiographs, even in the absence of symptoms. No significant association was found between response and any of the demographic variables in either question. Patients with a prior history of back surgery had similar response distributions for these 2 questions compared with new patients.

TABLE 4. Demographics of respondents to the following question: Would you be willing to undergo surgery if your $\mathrm{x}$-ray reports abnormalities, even if you do not have any symptoms?

\begin{tabular}{|c|c|c|c|c|}
\hline Parameter & All Responses & Yes & No & $p$ Value \\
\hline Total respondents (\%) & $116^{*}$ & $47(41)$ & $69(59)$ & - \\
\hline Average age \pm SD (yrs) & $54 \pm 16$ & $53 \pm 17$ & $54 \pm 15$ & $0.71 \dagger$ \\
\hline Sex $(\%)$ & & & & $0.09 \ddagger$ \\
\hline Males & $63(54)$ & $30(64)$ & $33(48)$ & \\
\hline Females & $53(46)$ & $17(36)$ & $36(52)$ & \\
\hline Education $(\%) \S$ & & & & $0.9 \ddagger$ \\
\hline High school & $42(36)$ & $17(36)$ & $25(36)$ & \\
\hline College & $44(38)$ & $19(40)$ & $25(36)$ & \\
\hline Graduate or professional & $29(25)$ & $11(23)$ & $18(26)$ & \\
\hline Received back surgery (\%) & & & & $0.42 \ddagger$ \\
\hline Yes & $37(32)$ & $13(28)$ & $24(35)$ & \\
\hline No & $79(68)$ & $34(72)$ & $45(65)$ & \\
\hline Date survey completed (\%) & & & & $0.96 \ddagger$ \\
\hline Before fungal meningitis outbreak & $67(58)$ & $27(57)$ & $40(58)$ & \\
\hline After fungal meningitis outbreak & $49(42)$ & $20(43)$ & $29(42)$ & \\
\hline
\end{tabular}

* Five survey participants did not answer and all 5 were excluded from analysis.

$\dagger$ Student t-test was used for group comparison.

$\ddagger$ Chi-square test of independence applied for group comparison.

$\S$ One survey participant did not report educational level and was excluded from chi-square analysis. 
Of the 59 patients stating they would have surgery based on an MRI abnormality, 19 (32\%) indicated they had previously received back surgery (Table 3 ). For the question regarding x-ray abnormalities, $13(28 \%)$ of the patients who responded affirmatively had previously undergone back surgery (Table 4).

A combined analysis of the responses to the 2 questions concerning radiological imaging revealed a statistically significant correlation $(\mathrm{p}<0.0001)$ between responses to the first and second questions (Table 5). A total of 114 respondents answered both questions concerning their willingness to undergo surgery based on radiological findings. Forty-six patients (40\%) indicated that, in the absence of symptoms, they would undergo surgery based on either x-ray or MRI abnormalities, while 54 (47\%) would not. Among the minority of patients responding differently to the 2 radiological questions, 13 patients $(11 \%)$ reported they would have surgery based on MRI abnormalities but not x-ray abnormalities (Table 5). There was no significant relationship between the combined patient responses to the 2 radiological questions and any of the demographic variables.

In addition to questions concerning patient response to radiological abnormalities, patients were asked questions regarding treatment of low-back pain. The first of these questions was, "Which is more effective to treat back pain (not leg pain)-back surgery or physical therapy?" Among the 109 participants who answered this question, $66(61 \%)$ believed physical therapy was more effective, 36 (33\%) believed back surgery was more effective, and $7(6 \%)$ believed both treatments were equally effective (Table 6). Among the patients who believed back surgery was more effective, the majority were men. However, $86 \%$ of those who believed both treatments were equally effective were female $(\mathrm{p}=0.047)$. Patients with high school education levels accounted for $50 \%$ of those who believed back surgery was more effective and $71 \%$ of those who believed both treatments were equally effective $(p=0.048)$. Finally, patients with a history of back surgery accounted for $42 \%$ of those who indicated that back surgery was more effective, $26 \%$ of those who believed physical therapy was more effective, and $71 \%$ of patients who thought both treatments were equally effective $(\mathrm{p}=0.026)$.

Patients were also asked to indicate whether they be-

TABLE 5. Comparison of responses to 2 survey questions*

\begin{tabular}{|c|c|c|c|}
\hline & \multicolumn{2}{|c|}{$\begin{array}{l}\text { Willing to Undergo Surgery w/ MRI } \\
\text { Abnormalities \& No Symptoms? }\end{array}$} & \multirow{2}{*}{$\begin{array}{c}p \\
\text { Value }\end{array}$} \\
\hline & Yes & No & \\
\hline $\begin{array}{l}\text { Willing to Undergo } \\
\text { Surgery w/ X-ray } \\
\text { Abnormalities \& No } \\
\text { Symptoms? }\end{array}$ & & & $<0.0001$ \\
\hline Yes & $46(40 \%)$ & $54(47 \%)$ & \\
\hline No & $13(11 \%)$ & $1(1 \%)$ & \\
\hline
\end{tabular}

* Two participants gave answers to 1 question but not the other and were excluded from analysis. Five survey participants did not answer both questions and were also excluded, leaving total 114 responses. The chi-square test was applied for group comparison. lieved that surgery or injections carried more risk, and 116 responses to this question were recorded and analyzed. Most patients (78\%) believed that back surgery was riskier. Twenty patients (17\%) believed back injections were more dangerous, and 5 patients (4\%) believed that the treatments were equally risky. No significant relationship was found between any of the demographic variables and response to this question (Table 7). Of the 20 patients responding that back injections were riskier, $10(50 \%)$ had undergone back surgery previously (Table 7). Finally, in all questions, no significant association was found between the fungal meningitis outbreak and patient response.

\section{Discussion}

Evaluations of health care outcomes are becoming increasingly important in clinical research and the national health care reform movement, particularly with respect to how health care quality is being measured and Pay-forPerformance initiatives. ${ }^{12,23}$ Recently there has been an increased focus on examining subjective and nontechnical dimensions of the patient experience, such as satisfaction and patient expectations. These investigations have begun to analyze patient perception both as a factor in determining clinical outcomes and as a measure of health care quality and physician performance. A number of studies have already demonstrated that patient satisfaction can directly and indirectly affect clinical outcomes., ${ }^{1,222}$ Although patient satisfaction likely depends on a number of different factors, it has been shown to be highly dependent on patient expectations for medical care. ${ }^{1,15,23}$ Previous research has shown that patients with one or more unmet expectations during a clinical encounter report reduced satisfaction, less clinical improvement, and decreased intention to adhere to physician recommendations. ${ }^{1}$ Thus, existing misconceptions and unrealistic expectations have the potential to alter patient satisfaction, the quality measures that measure it, and clinical outcomes themselves.

To better understand the prevalence of patient misconceptions in a general neurosurgery clinic, we administered a simple 6-question survey analyzing patient beliefs regarding the role of imaging findings in the context of appropriate treatment as well as relative effectiveness and risk of common treatment options for lumbar spondylosis. Our study demonstrated the existence of a number of misconceptions concerning the diagnosis and treatment of lumbar spondylosis within a patient population evaluated for neurosurgical consultation. These results are supported by previous research showing that misconceptions about lumbar spondylosis and its treatment are widespread and that many spondylosis patients have unrealistically high expectations for diagnosis and treatment. ${ }^{4,7}$ When treatment courses and clinical outcomes fail to meet these expectations, patients may be left feeling unsatisfied with their care. Furthermore, there is some evidence that positive patient expectations for recovery are related to better outcomes. ${ }^{16,22}$

One aspect of our survey specifically aimed to assess patient beliefs concerning the results of radiological imaging studies. With respect to treatment guidelines, the relationship between abnormalities in the lumbar spine and 
TABLE 6. Demographics of respondents to the following question: Which is more effective to treat back pain (not leg pain)?

\begin{tabular}{|c|c|c|c|c|c|}
\hline Parameter & All Responses & Back Surgery & Physical Therapy & Equally Effective & $\mathrm{p}$ Value \\
\hline Total respondents (\%) & $109^{*}$ & $36(33)$ & $66(61)$ & $7(6)$ & \\
\hline Average age \pm SD (yrs) & $54 \pm 16$ & $56 \pm 16$ & $52 \pm 16$ & $60 \pm 16$ & $0.3 \dagger$ \\
\hline Sex $(\%)$ & & & & & $0.047 \ddagger$ \\
\hline Males & $57(52)$ & $23(64)$ & $33(50)$ & $1(14)$ & \\
\hline Females & $52(48)$ & $13(36)$ & $33(50)$ & $6(86)$ & \\
\hline Education $(\%) \S$ & & & & & $0.048 \ddagger$ \\
\hline High school & $40(37)$ & $18(50)$ & $17(26)$ & $5(71)$ & \\
\hline College & $39(36)$ & $11(31)$ & $27(41)$ & $1(14)$ & \\
\hline Graduate or professional & $29(27)$ & $7(19)$ & $21(32)$ & $1(14)$ & \\
\hline Received back surgery (\%) & & & & & $0.026 \ddagger$ \\
\hline Yes & $37(34)$ & $15(42)$ & $17(26)$ & $5(71)$ & \\
\hline No & $72(66)$ & $21(58)$ & $49(74)$ & $2(29)$ & \\
\hline Date survey completed (\%) & & & & & $0.327 \ddagger$ \\
\hline Before fungal meningitis outbreak & $65(60)$ & $20(56)$ & $39(59)$ & $6(86)$ & \\
\hline After fungal meningitis outbreak & $44(40)$ & $16(44)$ & $27(41)$ & $1(14)$ & \\
\hline
\end{tabular}

* Twelve survey participants did not respond and were excluded from analysis.

$\dagger$ One-way ANOVA was used for group comparison.

$\ddagger$ Chi-square test of independence applied for group comparison.

$\S$ One survey participant did not report educational level and was excluded from chi-square analysis.

low-back pain is controversial. Given the high prevalence of radiological abnormalities and back pain, the discovery by MRI of bulges or protrusions in patients with low-back pain may frequently be coincidental. ${ }^{9}$ Thus, the decision to use invasive treatment in cases of lumbar spondylosis must be based on a preponderance of evidence, including thorough clinical assessment. Despite these general guidelines, our survey study showed that $40 \%$ of patients would elect to have surgery based on the results of either an MRI or radiographic imaging study in the absence of any symptoms. A smaller subset of survey respondents (11\%) indicated that they would undergo surgery based on MRI abnormalities but not those found on radiography.

Previous research has shown that patients highly value the results of radiological studies. A 2000 study concerning the views of patients with back pain found that a large pro-

TABLE 7. Demographics of respondents to the following question: What has more risk?

\begin{tabular}{|c|c|c|c|c|c|}
\hline Parameter & All Responses & Back Injections & Back Surgery & Equally Risky & $p$ Value \\
\hline Total respondents (\%) & $116^{*}$ & $20(17)$ & $91(78)$ & $5(4)$ & - \\
\hline Average age $\pm \mathrm{SD}$ (yrs) & $54 \pm 16$ & $55 \pm 13$ & $54 \pm 17$ & $50 \pm 12$ & $0.8392^{* *}$ \\
\hline $\operatorname{Sex}(\%)$ & & & & & $0.67 \dagger$ \\
\hline Males & $61(53)$ & $12(60)$ & $47(52)$ & $2(40)$ & \\
\hline Females & $55(47)$ & $8(40)$ & $44(48)$ & $3(60)$ & \\
\hline Education (\%)‡ & & & & & $0.3 \dagger$ \\
\hline High school & $44(38)$ & $6(30)$ & $34(37)$ & $4(80)$ & \\
\hline College & $43(37)$ & $9(45)$ & $34(37)$ & $0(0)$ & \\
\hline Graduate or professional & $28(24)$ & $5(25)$ & $22(24)$ & $1(20)$ & \\
\hline Received back surgery (\%) & & & & & $0.18 \dagger$ \\
\hline Yes & $38(33)$ & $10(50)$ & $27(30)$ & $1(20)$ & \\
\hline No & $78(67)$ & $10(50)$ & $64(70)$ & $4(80)$ & \\
\hline Date survey completed (\%) & & & & & $0.26 \dagger$ \\
\hline Before fungal meningitis outbreak & $68(59)$ & $15(75)$ & $50(55)$ & $3(60)$ & \\
\hline After fungal meningitis outbreak & $48(41)$ & $5(25)$ & $41(45)$ & $2(40)$ & \\
\hline
\end{tabular}

* Five survey participants did not respond and were excluded from analysis.

** One-way ANOVA for equality of means was used for group comparison.

$\dagger$ Data are presented as raw number of survey participants; the chi-square test of independence was applied for group comparison.

$\ddagger$ One survey participant did not report educational level. 
portion of these patients rated radiological images as very important. ${ }^{18}$ More specifically, a study of patient education aids found that $70 \%$ of patients believed CT or MRI results were more important than a physician's examination in deciding the appropriateness of surgical intervention. ${ }^{3}$ One reason for the perceived importance of radiological tests may be that patients harbor unrealistic expectations for the diagnostic capabilities of such tests. A Norwegian study found that $42 \%$ of respondents believed that x-ray and other imaging tests can always identify the cause of back pain. Furthermore, this study showed that while other back pain-related "myths" are fading, those concerning the use of imaging tests may actually be increasing. These data indicate that many patients present at clinic with a number of aberrant beliefs and expectations concerning the use of diagnostic imaging. Failure to meet these expectations may lead to decreased patient satisfaction, which itself can lead to poorer clinical outcomes and provider performance reviews. This presents physicians with a difficult situation as they try to reconcile attempts to provide sound medical advice with the need to meet patient expectations.

In addition to surveying patient beliefs on the use of radiology, we also examined patient beliefs regarding the relative risk and effectiveness of various treatments for low-back pain. Presently, there is no conclusive evidence whether nonoperative management or surgery is most effective for back pain due to disc degeneration. Given its invasiveness, surgery is typically recommended for patients who fail nonoperative management, including physical therapy and/or injections. Thirty-three percent of our respondents indicated they believe back surgery is more effective for the treatment of back pain (not leg pain) than physical therapy. While the cause of this misconception is complicated and multifactorial, misinformation from other physicians, incorrect interpretation or recall of provider information, and patient-performed research may play a role. ${ }^{14}$ A lumbar spondylosis study from the United Kingdom found that patients who had visited a general practitioner expressed more misconceptions concerning spondylosis and its treatment than those who had not. The study additionally found that those who consulted with a general practitioner were often not reassured by their consultation and maintained their misconceptions. ${ }^{10}$ A separate study found that patients with spondylosis are often highly dissatisfied with the amount and quality of information they are provided by physicians. ${ }^{14}$ This may prompt personal efforts by the patient to seek information on their own from the Internet and other sources, further complicating the confusion.

In agreement with current treatment guidelines, most patients responded that back surgery was riskier than back injections. However, $17 \%$ of survey respondents indicated that back injections are risker than back surgery. Risk perception studies have found that patients use a number of cognitive processes in the assessment of risk, many of which are inherently biased. Literature on the subject of patient perception of risk has shown that people's interpretation of risk information is guided primarily by heuristics. People judge events that are more easily brought to mind as more probable..$^{13,20}$ In this view, mental associations with surgical imagery may be the reason for the per- ceived risk of surgery. Additionally, research has shown that patients may reduce risk to a simple categorization as either dangerous or safe. Patients indicating that back injections are riskier may have simply categorized them as such at a given point and have not since reevaluated their judgment. The framing and style of the presentation of risk information has also been shown to affect risk perception. Finally, patients are also simply prone to forget much of the risk information presented. ${ }^{13}$

Interestingly, for every question asked, patients with a previous history of back surgery continued to harbor many of the same misconceptions as new patients, despite the fact that these patients had already undergone consultation leading up to their previous surgery. Patients with a history of prior back surgery accounted for nearly a third of the respondents who indicated they would have surgery based on radiological abnormalities in the absence of any symptoms. Patients who had experienced back surgery also accounted for half of the respondents that believed back injections were riskier than back surgery, and nearly half of those who believed back surgery was more effective than physical therapy for the treatment of back pain. Previous research has shown that patients with higher grades of pain more strongly believed that all back pain patients should receive radiological testing and held more misconceptions than patients with lower pain grades. ${ }^{4}$ Patients with back pain requiring prior surgery may have more pain and thus be prone to more misconceptions than patients with new back pain. As discussed above, studies have also cited conflicting information from various health care providers as a potential source of patient misconceptions. ${ }^{14}$ Patients with a history of back surgery likely consulted many health care providers in the course of their treatment and may be more susceptible to misconceptions stemming from providers. Finally, providing adequate information to patients remains a crucial and unresolved issue in the treatment of lumbar spondylosis. ${ }^{6}$ Therefore, many of these repeat patients may have simply not received adequate information during prior consultations.

While the extent of the misconceptions demonstrated here and their sources are likely complex, their existence signals a general need for more effective provider-patient communication. A review of studies on physician-patient communication and health outcomes found that the quality of communication during patient visits influenced health outcomes such as patient emotional health, symptom resolution, and pain control. ${ }^{21}$ A separate review showed that more effective communication improved patient recall of information, adherence to recommendations, and attendance at clinical appointments. ${ }^{5}$ Additionally, providerpatient communication has been shown to affect patient satisfaction itself. While it is difficult to define what constitutes "enhanced communication," increased consultation length, information booklets, patient coaching, and informational videos have all been used with some success. ${ }^{21}$

There are some potential sources of error and limitations to the present study. First, the population surveyed in our study was rather small, limiting our ability to draw concrete conclusions from the data. However, patient demographics were similar to those of the general population, and we feel provide a representative sample. The am- 
biguity of the questions may be considered a limitation, but it allowed the investigators to elicit unguided perceptions from the surveyed patients. Questions were designed to ensure clarity by being concise, straightforward, and multiple choice, although we understand that the multiple-choice nature of the questions may have excessively limited the scope of patient response. More importantly, while this study was designed to highlight the existence of a number of misconceptions concerning back pain and its treatment, the factors contributing to these misconceptions will be important to elucidate. Further research is necessary to determine the major influences contributing to patient understanding of this condition, and is the subject of current analysis.

\section{Conclusions}

A large and complex disparity exists between patient understanding of degenerative spinal disease and current medical knowledge of spine pathology and indications for surgery. A large percentage of patients indicated they would elect to have surgery based on the results of radiological studies in the absence of any symptoms. Furthermore, a significant portion of patients harbored misconceptions regarding the relative risk and effectiveness of various low-back pain treatments. Finally, these misconceptions persisted in patients with a prior history of back surgery. Although the data presented here are preliminary, the implications of such results are significant. These results show that a surprisingly high percentage of patients have misconceptions regarding surgical treatment. This lack of understanding may not be specifically addressed in the surgical consultation, leaving the patient with a perception of unmet expectations and decreased patient satisfaction.

\section{References}

1. Bell RA, Kravitz RL, Thom D, Krupat E, Azari R: Unmet expectations for care and the patient-physician relationship. J Gen Intern Med 17:817-824, 2002

2. Cleary PD, McNeil BJ: Patient satisfaction as an indicator of quality care. Inquiry 25:25-36, 1988

3. Deyo RA, Cherkin DC, Weinstein J, Howe J, Ciol M, Mulley AG Jr: Involving patients in clinical decisions: impact of an interactive video program on use of back surgery. Med Care 38:959-969, 2000

4. Goubert L, Crombez G, De Bourdeaudhuij I: Low back pain, disability and back pain myths in a community sample: prevalence and interrelationships. Eur J Pain 8:385-394, 2004

5. Harrington J, Noble LM, Newman SP: Improving patients' communication with doctors: a systematic review of intervention studies. Patient Educ Couns 52:7-16, 2004

6. Henrotin YE, Cedraschi C, Duplan B, Bazin T, Duquesnoy $B$ : Information and low back pain management: a systematic review. Spine (Phila Pa 1976) 31:E326-E334, 2006

7. Ihlebaek C, Eriksen HR: Myths and perceptions of back pain in the Norwegian population, before and after the introduction of guidelines for acute back pain. Scand J Public Health 33:401-406, 2005

8. Jenkinson C, Coulter A, Bruster S: The Picker Patient Experience Questionnaire: development and validation using data from in-patient surveys in five countries. Int J Qual Health Care 14:353-358, 2002

9. Jensen MC, Brant-Zawadzki MN, Obuchowski N, Modic MT, Malkasian D, Ross JS: Magnetic resonance imaging of the lumbar spine in people without back pain. N Engl J Med 331:69-73, 1994

10. Klaber Moffett JA, Newbronner E, Waddell G, Croucher K, Spear S: Public perceptions about low back pain and its management: a gap between expectations and reality? Health Expect 3:161-168, 2000

11. Leape LL, Berwick DM: Five years after To Err Is Human: what have we learned? JAMA 293:2384-2390, 2005

12. Linskey ME: Neurosurgery quality: pay-for-performance, guidelines, and outcome measures. Clin Neurosurg 54:157179,2007

13. Lloyd AJ: The extent of patients' understanding of the risk of treatments. Qual Health Care 10 (Suppl 1):i14-i18, 2001

14. McIntosh A, Shaw CF: Barriers to patient information provision in primary care: patients' and general practitioners' experiences and expectations of information for low back pain. Health Expect 6:19-29, 2003

15. McKinley RK, Stevenson K, Adams S, Manku-Scott TK: Meeting patient expectations of care: the major determinant of satisfaction with out-of-hours primary medical care? Fam Pract 19:333-338, 2002

16. Myers SS, Phillips RS, Davis RB, Cherkin DC, Legedza A, Kaptchuk TJ, et al: Patient expectations as predictors of outcome in patients with acute low back pain. J Gen Intern Med 23:148-153, 2008

17. Myles PS, Williams DL, Hendrata M, Anderson H, Weeks AM: Patient satisfaction after anaesthesia and surgery: results of a prospective survey of 10,811 patients. Br J Anaesth 84:6-10, 2000

18. Phelan EA, Deyo RA, Cherkin DC, Weinstein JN, Ciol MA, Kreuter W, et al: Helping patients decide about back surgery: a randomized trial of an interactive video program. Spine (Phila Pa 1976) 26:206-212, 2001

19. Sitzia J, Wood N: Patient satisfaction: a review of issues and concepts. Soc Sci Med 45:1829-1843, 1997

20. Slovic P, Peters E: Risk perception and affect. Curr Dir Psychol Sci 15:322-325, 2006

21. Stewart MA: Effective physician-patient communication and health outcomes: a review. CMAJ 152:1423-1433, 1995

22. Verbeek J, Sengers MJ, Riemens L, Haafkens J: Patient expectations of treatment for back pain: a systematic review of qualitative and quantitative studies. Spine (Phila Pa 1976) 29:2309-2318, 2004

23. Williams B: Patient satisfaction: a valid concept? Soc Sci Med 38:509-516, 1994

\section{Author Contributions}

Conception and design: Yang, Park. Acquisition of data: Yang, Franz, Bentley, Yee, Chang, Kendall-Thomas. Analysis and interpretation of data: Yang, Franz, Bentley, Yee, Chang, KendallThomas. Drafting the article: Yang, Franz, Bentley, Yee, Chang, Kendall-Thomas. Critically revising the article: Yang, Park. Reviewed submitted version of manuscript: all authors. Approved the final version of the manuscript on behalf of all authors: Yang. Study supervision: Yang, Kendall-Thomas, Park.

\section{Supplemental Information \\ Previous Publication}

Portions of this work were presented on March 7, 2014, as an oral platform at the Annual AANS/CNS Meeting, Section on Disorders of the Spine and Peripheral Nerves, in Orlando, Florida.

\section{Correspondence}

Lynda J. S. Yang, Department of Neurosurgery, University of Michigan, 1500 E. Medical Center Dr., 3552 Taubman Center, Ann Arbor, MI 48109-5338. email: ljsyang@med.umich.edu. 